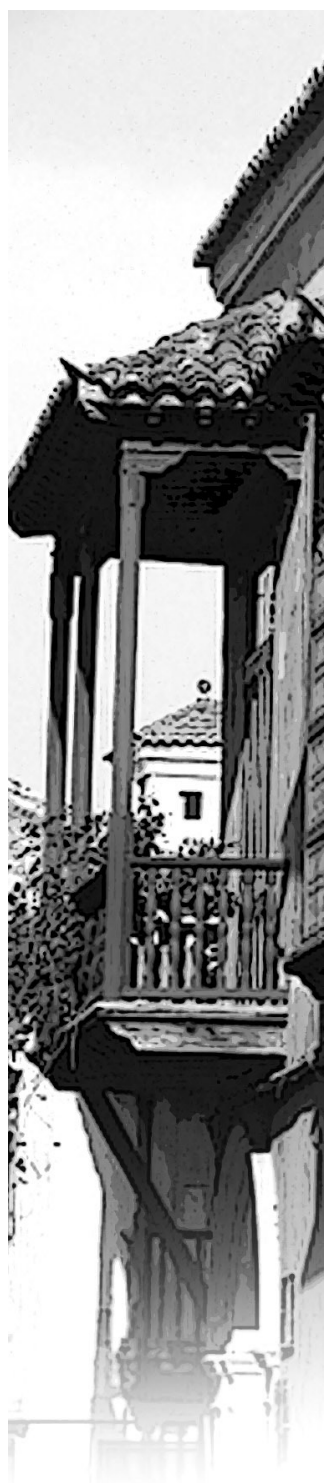

\title{
LA “GACETA MÉDICA" DE LA SOCIEDAD DE MEDICINA Y CIENCIAS NATURALES DE BOLÍVAR (1888-1919)
}

\section{MONTERROSA-CASTRO ÁLVARO}

Gaceta Médica fue el órgano de información de la Sociedad de Medicina y Ciencias Naturales de Bolívar, fundada en 1888 que por ordenanza departamental cambio su nombre al de Academia de Medicina de Cartagena, el 25 de marzo de 1918. Así se conoce hoy día.

Este libro del doctor Álvaro Monterrosa Castro describe de manera detallada y minuciosa dicha sociedad entre los años 1888 y 1919 , en más de doscientas cincuenta páginas varias ilustraciones y reseñas documentales, distribuidas en 11 capítulos: (1) origen y los primeros pasos de la Sociedad de medicina y Ciencias Naturales de Bolívar; (2) los primeros seis números de Gaceta Médica; (3) Cirugía conservadora, medica, ambiente y ciudad; (4) Lombrices, hemorroides y

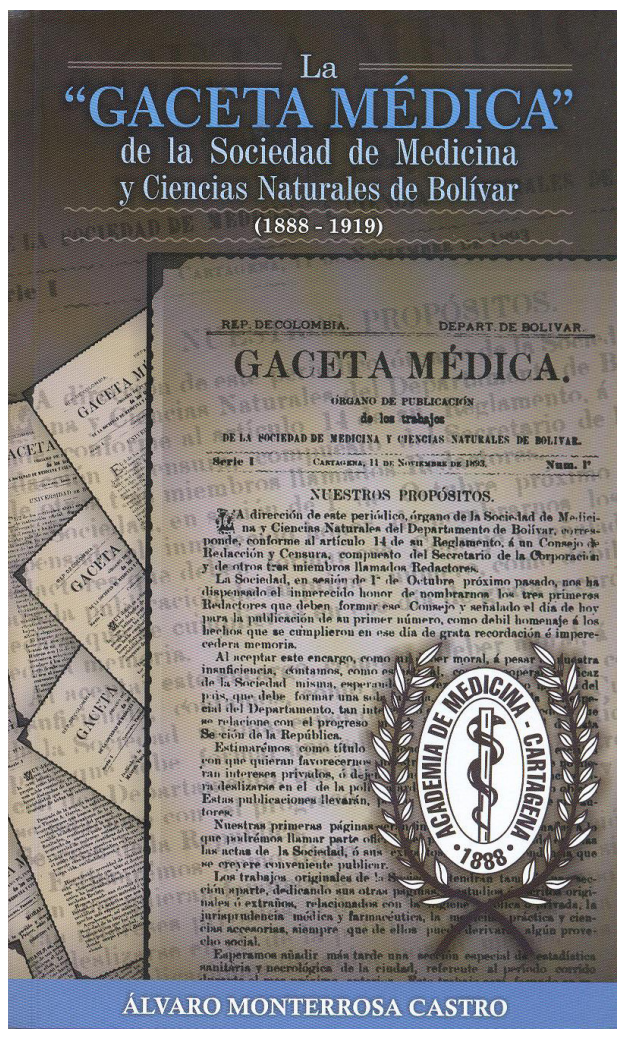
elefantiasis; (5) Rafael Calvo Lamadrid: un cupo en la inmortalidad; (6) desde el primer aniversario hasta laboremus; (7) la higiene pública y la semiología: en el epicentro; (8) las enfermedades infecciosas a la orden del día; (9) la serie III de Gaceta Médica: del número 25 al 33; (10) Receso por la guerra de los mil días y reorganización en el siglo XX, y (11) La segunda época de la Gaceta Medica y la Academia de Medicina de Cartagena.

En esos capítulos el autor trata diferentes aspectos de algunos de los artículos presentes en Gaceta Médica, como patologías infecciosas, la cirugía, los conceptos de higiene y la lepra; al tiempo, relata la historia de la Sociedad que realizó la publicación, mostrando las cualidades humanas de los gestores, sus opiniones, pensamientos y conocimientos.

El capítulo sobre el receso de la Sociedad y del periódico como consecuencia de la Guerra de los Mil Días aporta documentos, datos e 
información sobre las escaramuzas que se dieron en las vecindades de Cartagena, y cuenta la participación en el conflicto de algunos integrantes de la Sociedad al interior de las "ambulancias gubernamentales". Ello no había sido descrito antes en la historia de la medicina colombiana y es una valiosa contribución que realiza el autor.

El profesor Álvaro Monterrosa Castro es titular en la Facultad de Medicina de la Universidad de Cartagena.

\section{MANUAL DEL TRABAJO SEGURO EN ALTURAS}

\section{BEDOYA-MARRUGO ELÍAS ALBERTO}

Desde el inicio de la historia, el ser humano siempre buscó la manera de sobrevivir mediante la elaboración de herramientas como piedras y lanzas para capturar a sus presas; algunas, de gran tamaño, le ocasionaban lesiones y bajas en sus grupos de caza. En virtud de ello, indagaba sobre cómo protegerse de todos los peligros a los que estaba expuesto para evitar lastimarse.

Con el transcurrir del tiempo, las personas continuaron buscando las manera de cuidar su vida en todos los entornos, principalmente en el ámbito laboral. Con la Revolución Industrial se dio el despertar para encontrar alternativas que protegieran al trabajador dentro y fuera de una empresa.

De manera especial, vale destacar que en los diferentes sectores económicos, se señalan con frecuencia las lesiones sufridas en altura por los trabajadores. En la realización de sus labores, ellos sólo tenían como forma de protección amarrarse en zonas del cuerpo como cintura y los pies, lo que no los dejaba exentos de una lesión grave al caer de una altura considerable.

Por esta razón, en su afán de proteger y salvaguardar la vida del trabajador, se diseñan elementos de protección como el cinturón liniero, una medida para detener la caída del hombre durante el desarrollo de su actividad. Sin embargo, se necesitaba desarrollar otros elementos tecnológicos para que la lesión producida por la caída no fuese considerable ni dañara la integridad de la persona. Los avances descartaron este elemento, considerado poco eficiente para proteger al trabajador que, en eventuales circunstancias, podía morir a causa de una caída de altura.

El profesor Elías Alberto Bedoya Marrugo es docente catedrático en el programa de enfermería de la Universidad de Cartagena.

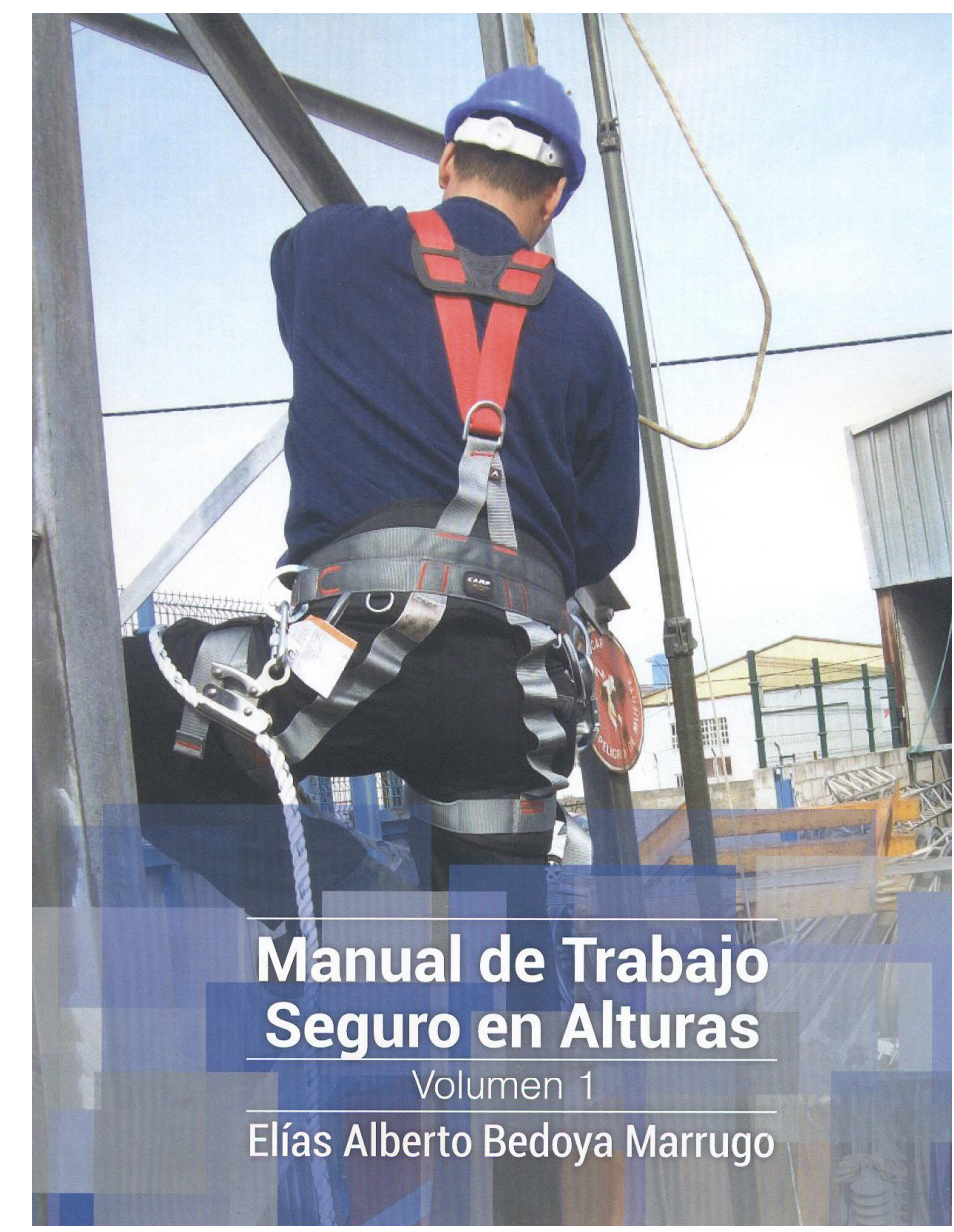

